This document is published in:

Ardila-Rey, J.A.; Martinez-Tarifa, J.M.; Robles, G.; Rojas-Moreno, M.; Albarracin, R.; , "A Partial Discharges acquisition and statistical analysis software," Instrumentation and Measurement Technology Conference (I2MTC), 2012 IEEE International , pp. 1670-1675, 13-16 May 2012. DOI: 10.1109/I2MTC.2012.6229187

(C) 2012 IEEE. Personal use of this material is permitted. Permission from IEEE must be obtained for all other uses, in any current or future media, including reprinting/republishing this material for advertising or promotional purposes, creating new collective works, for resale or redistribution to servers or lists, or reuse of any copyrighted component of this work in other works. 


\title{
A Partial Discharges Acquisition and Statistical Analysis Software
}

\author{
Ardila-Rey, J.A.; Martínez-Tarifa, J.M.; Robles, G.; Rojas-Moreno, M; Albarracín, R. \\ Department of Electrical Engineering \\ Universidad Carlos III de Madrid \\ Leganés (Madrid), España \\ jmmtarif@ing.uc3m.es
}

\begin{abstract}
Partial Discharges (PDs) are responsible for unexpected failures in power system equipment, so their measurement is a fundamental tool for electrical equipment maintenance. In order to characterize PDs activity, some statistical magnitudes are necessary. For this purpose, PDs acquisition and processing is an important tool for critical decisions related to power systems. In this paper, the main difficulties and challenges facing PDs detection, acquisition and processing are presented. Results will be compared to a commercial PDs detection system.
\end{abstract}

Keywords- PD pulse waveform; partial discharge; synchronism signal; detection algorithm; zero crossing detector.

\section{INTRODUCTION}

Electrical insulation is one of the most important sources of unexpected failures in electrical equipment. It is well known that voltages cannot exceed rated values to avoid electrical breakdown of insulation systems. However, even rated voltages are able to create Partial Discharges (PDs) in power cables and electrical machines. These discharges are low energy electrical breakdown phenomena that take place in highly divergent electrical fields regions and inhomogeneous sites within a solid dielectric [1],[2].

Partial discharges do not cause immediate failures but contribute to degrade insulation systems by means of chemical and physical attack of the surroundings of the main solid dielectric [3]. This leads to premature failures in electrical equipment, because partial discharges take place several times per power frequency cycle.

Thus, PDs detection has become one of the principal qualifying tests for power system assets management [2],[4]. Traditionally, PDs activity has been represented as pulses (in $\mathrm{pC}$ or $\mathrm{mV}$ ) superimposed to power frequency applied voltage with the aim of classifying their sources. These so-called Phase Resolved Partial Discharge (PRPD) patterns require the acquisition of many PDs cycles of pulse activity, since these change for the same applied voltage due to environmental conditions, insulation ageing status, and availability of free electrons among others. The partial discharge is a stochastic phenomenon and its parameters must be treated statistically [5],[6]. The most common statistical tool to characterize PDs amplitudes is the Weibull cumulative probability distribution $P(q)$.

This research has been supported by the Spanish Science and Technology Ministry under Contract No. DPI 2009-14628-C03-02 and by the Madrid Regional Government and Universidad Carlos III de Madrid under Contract No. CCG10-UC3M/DPI-4627. Tests have been carried out in the High Voltage Research and Tests Laboratory at Universidad Carlos III de Madrid (LINEALT).
$P(q)=1-e^{-\left(\frac{q}{\alpha}\right)^{\beta}}$

Where $P(q)$ is the probability of having a discharge with an amplitude equal or below $q, \alpha$ is the characteristic value of the discharge amplitude $(P(q=\alpha)=0.6321)$ and $\beta$ is the shape factor whose value is higher when the distribution is less dispersive. Parameters $\alpha$ and $\beta$ can be obtained from the calculation of the least square linear regression of logarithms applied to $(1-P(q))$ [7]. Another statistical amplitude that provides interesting information is $Q_{\max 95 \%}$, which is the charge magnitude below which are the $95 \%$ of the detected discharges. In addition to this, the number of detected pulses ( $N_{w}$ when referred per cycle) must be recorded too in order to estimate the number of PDs sites in real insulation systems.

For all these reasons, computer aided data acquistion is necessary to analyse PRPD patterns. This allows having quantitative results when measuring partial discharges that can support costly decissions about disconnections of power system equipments. Most of these commercial systems detect PRPD patterns and store the information in hard disks for future analysis with different processing (statistical calculations) software.

As PDs detection is usually made in industrial environments where electrical noise is present, advanced noise rejection techniques are necessary for PDs measurement and interpretation [8]. Following this trend, pulse waveforms analysis is recently used to help in noise separation and classification [8]-[10]. These processes require the use of wider band acquisition data systems and sensors (up to 50 $\mathrm{MHz}$ ).

The acquisition software presented in this paper displays PRPD patterns and PDs waveforms. Additionally, it processes discharges from PRPD patterns to get the statistical parameters explained above storing these data in RAM. The results presented here will be compared to those from a commercial PDs detection system.

\section{ACQUISITION SYSTEM STRUCTURE}

The features of the acquisition system are: 
- Displays classical patterns of partial discharges (phase angle $\varphi$-amplitude).

- Displays PDs pulse waveforms in real time.

- Calculates statistical parameters from the acquisition of a set of signals when required.

- Interactively with the user, adjusts the minimum level of discharge magnitude detected (trigger level) and the maximum pulse amplitude detected in the visualization window (full scale).

Fig. 1 shows the schematic diagram of the internal structure of the code used in the acquisition system which takes into account four basic steps:

Acquisition: A Zero Crossing Detector (ZCD) sets the starting time of the acquisition of PDs pulse signals according to the synchronization with the grid reference signal at $50 \mathrm{~Hz}$.

Peak detection: Identifies the polarity, amplitude and phase of PDs pulses through a detection algorithm.

Display and storage: Shows in real time the PD pulse waveform and the classical patterns of the partial discharges superimposed to the synchronism signal; these data (amplitudephase) are stored in RAM for subsequent analyses [11].

Processing (under user request): Processes the data provided by the previous step and calculates several statistical parameters such as the number of pulses and Weibull constants. This is done while the acquisition continues without using different processing software (avoiding storing data in a hard disk).

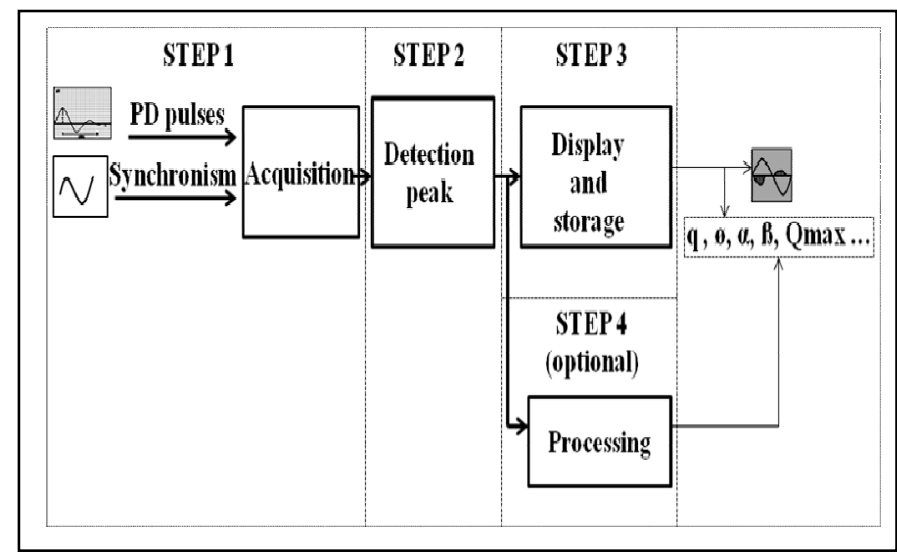

Figure 1. Schematic diagram of the acquisition system.

The programming tool used for this application is Labview 8.6. The data acquisition card used is a NI-5105, 8-channel digitizer with $60 \mathrm{MS} / \mathrm{s}$ sampling frequency per channel simultaneously, inserted in a CPU with an AMD Athlon $64 \times 2$ Dual Core processor and 2.0 GB of RAM.

\section{EXPERIMENTAL SETUP}

Partial discharges were created by applying high voltage to several test objects. Dielectric materials show a capacitive behavior so, to detect discharge pulses, a capacitive divider branch is used to provide a low impedance path for these transient currents that are measured using commercial High Frequency Current Transformers (HFCT) (see Fig. 2). A commercial PDs detection system (PD_CHECK from TechImp Systems S.r.l.) was also used to measure PRPD patterns and pulse waveforms with the aim of comparing results.

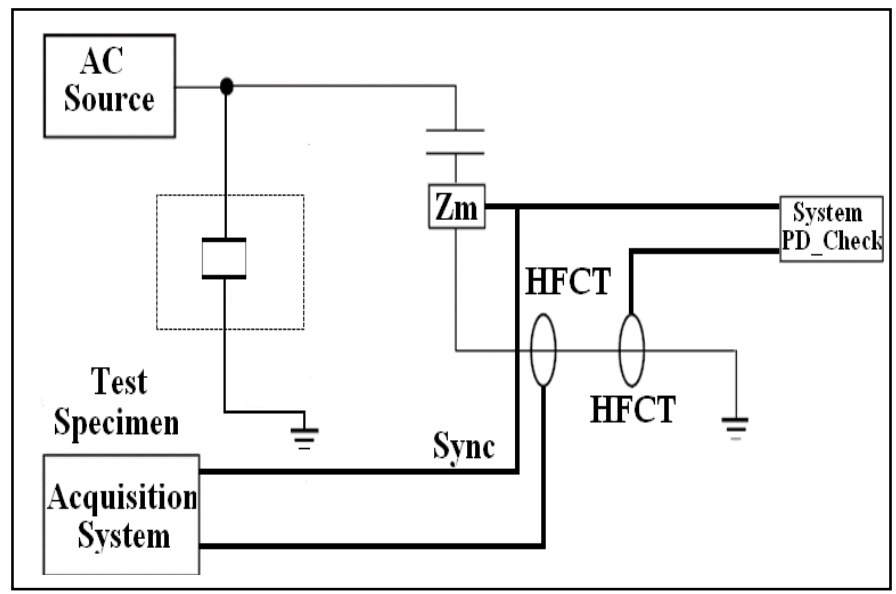

Figure 2. PDs detection circuit.

The test objects selected to have control on PDs activity were:

- Point-air-plane configuration. In this particular case, a needle $0.5 \mathrm{~mm}$ thick was placed $1 \mathrm{~mm}$ above a metallic ground plane. It is well known that highly divergent electrical fields, lead to a special kind of partial discharges known as corona discharges [1].

- Twisted pair of enameled magnet wires. In this test object, it is very common to see surface partial discharges similar to those present in turn to turn electrical insulation in electrical machines.

- Oil-paper insulation system. Five pieces of insulating paper $0.1 \mathrm{~mm}$ thick were immersed in mineral oil. They are placed between two heavy metallic electrodes that press together the paper sheets.

During the acquisitions, pulses that are not correlated in phase with the synchronization voltage, or those that arise for voltages below $800 \mathrm{~V}$ are defined as noise. Before starting the measurement process, this noise is filtered setting an appropriate trigger level, eliminating signals that were acquired below the threshold level (around $1.5 \mathrm{mV}$ for these tests). Afterwards, the applied high voltage was increased progressively until the PDs Inception Voltage (PDIV) was reached. Once PDs activity was stable (after 15 minutes above the PDIV), measurements were taken.

\section{CHALLENGES FACED IN THE ACQUISITION}

\section{A. Amplitude, Polarity and Phase Identification of the PD Pulse}

The waveform of the partial discharges varies considerably depending on the test object, the applied voltage and the measuring setup. It is very important for the acquisition system 
to be sufficiently flexible to avoid mistakes in the identification of the amplitude, polarity and phase of the acquired PD pulses.

When measuring PD waveforms, sometimes the maximum value is followed or preceded by several oscillations (see example in Fig. 3). These minor peaks of the signal should be ignored when viewing and storing the main peak amplitude (which is directly related to the apparent charge) and polarity of pulse.

In order to detect PD pulse peaks, a volatile matrix was used to identify waveform maxima and minima. In this matrix, pulse peaks magnitudes, polarities and times above the fixed threshold (trigger) are stored for each discharge waveform (Fig. 4) during a maximum acquisition time of $1 \mu \mathrm{s}$.

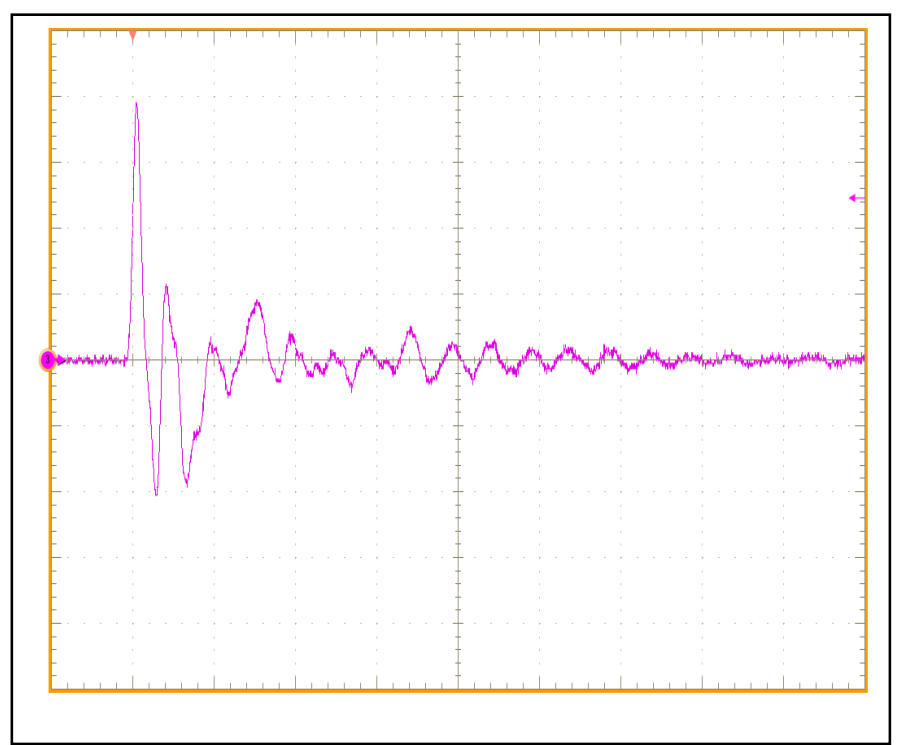

Figure 3. Typical PD pulse detected with an inductive device in the oscilloscope.

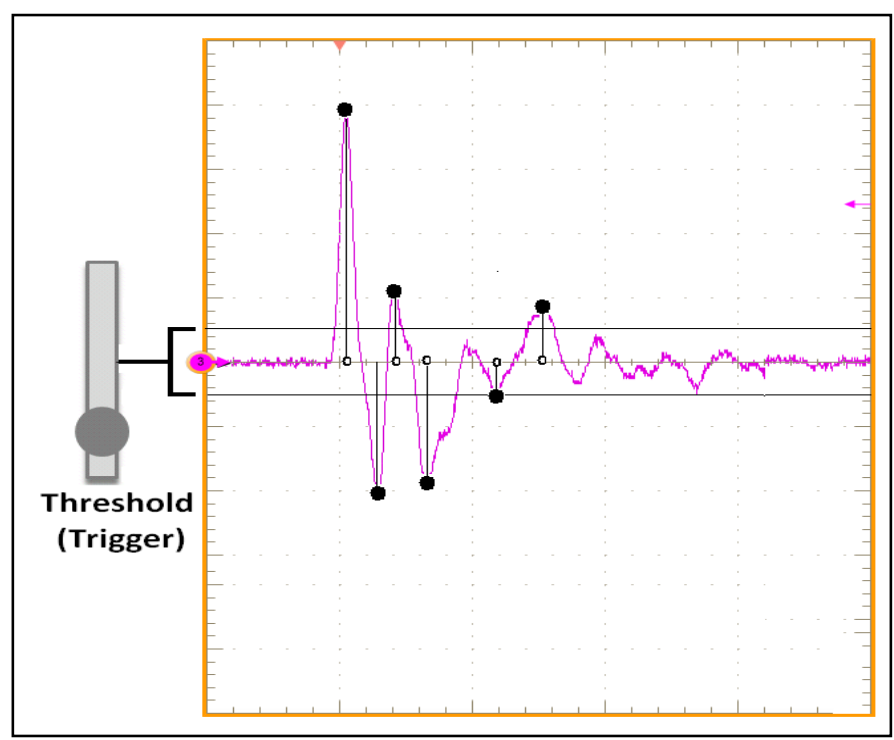

Figure 4. Identification of maxima and minima in a PD waveform.
Afterwards, the maximum value from this matrix is selected to be represented in the PRPD plot using three parameters: maximum magnitude, polarity (if the maximum value was negative) and time occurrence (referred to synchronization voltage, leading to phase). Signed PD pulse magnitude, polarity and phase are then stored in a non-volatile matrix for PRPD representation and statistical calculation. Thus, the "waveform matrix" is erased and updated with new data for each pulse waveform acquisition, and the "PRPD matrix" is continuously adding new data (only can be reset by the user) from the peak location algorithm based on the "waveform matrix".

The trigger level is set symmetrically by the user for both positive and negative pulses using the same magnitude for both possibilities.

After each pulse acquisition, a PD event counter is refreshed inside the program and displayed at screen for the final user. The counter can be reset by the user as well.

\section{B. Phase of the PD Pulse}

A critical parameter in the analysis of partial discharges is the phase angle $\varphi$. Any error in its measurement would bring serious problems in the correct representation of the PRPD patterns. To solve this difficulty, a sinusoidal signal of $50 \mathrm{~Hz}$ (see Fig. 2) was used as synchronism for the ZCD incorporated into the detection algorithm.

Basically, the mentioned ZCD is a software routine that detects the first polarity change in the reference signal. This will be used as the time reference for phase identification. The cycle on which occurred the discharge is detected by means of a counter which stores the amount of cycles for a subsequent analysis (for example $N_{w}$ ).

\section{Further Improvements for the Acquisition Speed}

In order to avoid the activation of the acquisition two times per cycle, the ZCD was configured to do a single reading every $20 \mathrm{~ms}$ starting at the instant when high voltage signal crosses its first zero and neglecting the crossing at the middle of the cycle. Then, the acquisition block (see Fig. 1) has to be activated only once per cycle. This resulted in a higher acquisition speed that allowed storing more pulses per cycle.

\section{Display of the PD Pulse Waveform}

To display the PD pulse waveform properly it is necessary to know the time when the PD pulse exceeded the trigger level, $T_{P D}$. This time is used to control the maximum and minimum time represented of the graph. The user will be able to configure:

- The time length of the graph: $\Delta T_{L}$ has optional predefined values: $0.1 \mu \mathrm{s}, 1 \mu \mathrm{s}, 5 \mu \mathrm{s}$ and $10 \mu \mathrm{s}$.

- The Pre-trigger interval, $\triangle P T$ : Is a percentage of $\Delta \mathrm{T}_{\mathrm{L}}$. Indicates the fraction of time that begins displaying before the partial discharge occurred.

For this system, the minimum and maximum times represented in the graph are established by (2) and (3). 


$$
\begin{aligned}
& \mathrm{T}_{\text {min }}=\mathrm{T}_{\mathrm{PD}}-\Delta \mathrm{PT} \\
& \mathrm{T}_{\text {max }}=\mathrm{T}_{\mathrm{PD}}+\left(\Delta T_{L}-\Delta \mathrm{PT}\right)
\end{aligned}
$$

Being $T_{\min }$ the minimum time and $T_{\max }$ the maximum time. Fig. 5 resumes these parameters.

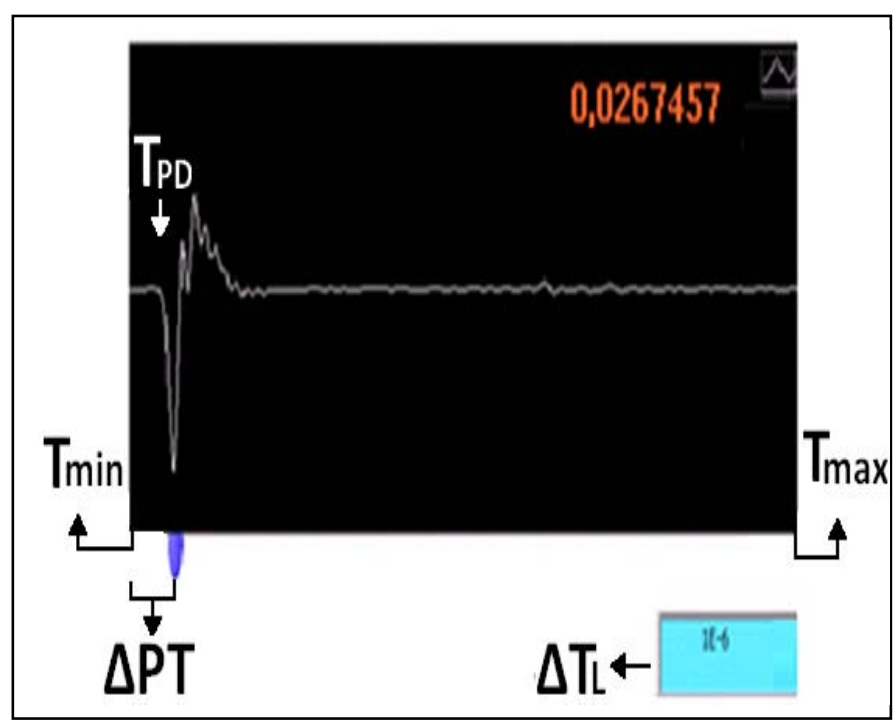

Figure 5. Waveform of the PD Pulse .

\section{ANALYSIS AND COMPARISON OF RESULTS}

Tests were carried out simultaneously with the proposed acquisition systems PD LINEALT and PD CHECK, until approximately the same number of pulses were recorded in both of them.

\section{A. Corona Discharges}

Table I and Fig. 6 show the results obtained for both systems using the test object point-air-plane at $1.7 \mathrm{kVrms}$. There are strong similarities in the statistical parameters and the PRPD patterns validating the algorithms used in the proposed system.

TABLE I. COMPARISON OF DATA FROM PROPOSED SYSTEM AND PD_CHECK FOR TEST OBJECT POINT-AIR-PLANE $(\mathbf{1 . 7} \mathbf{~ K V})$

\begin{tabular}{|l|c|c|l|c|c|}
\hline \multicolumn{3}{|c|}{ PD_LINEALT } & \multicolumn{3}{c|}{ PD_CHECK } \\
\hline $\begin{array}{l}\text { HALF } \\
\text { CYCLE }\end{array}$ & + & - & $\begin{array}{l}\text { HALF } \\
\text { CYCLE }\end{array}$ & + & - \\
\hline $\begin{array}{l}\text { N } \\
\text { DISCHARGES }\end{array}$ & 558 & 2496 & $\begin{array}{l}\text { N } \\
\text { DISCHARGES }\end{array}$ & 663 & 3028 \\
\hline $\boldsymbol{\alpha}(\mathbf{V})$ & 0.022 & 0.0040 & $\boldsymbol{\alpha}(\mathbf{V})$ & 0.0543 & 0.0068 \\
\hline $\boldsymbol{\beta}$ & 6.106 & 3.470 & $\boldsymbol{\beta}$ & 5.730 & 3.8240 \\
\hline $\mathbf{Q}_{\max 95 \%(\mathbf{V})}$ & 0.0325 & 0.005 & $\mathbf{Q}_{\max 95 \%}(\mathbf{V})$ & 0.0711 & 0.0125 \\
\hline $\mathbf{N}_{\mathbf{W}}$ & 2.15 & 9.6 & $\mathbf{N}_{\mathbf{W}}$ & 2.2 & 10 \\
\hline
\end{tabular}

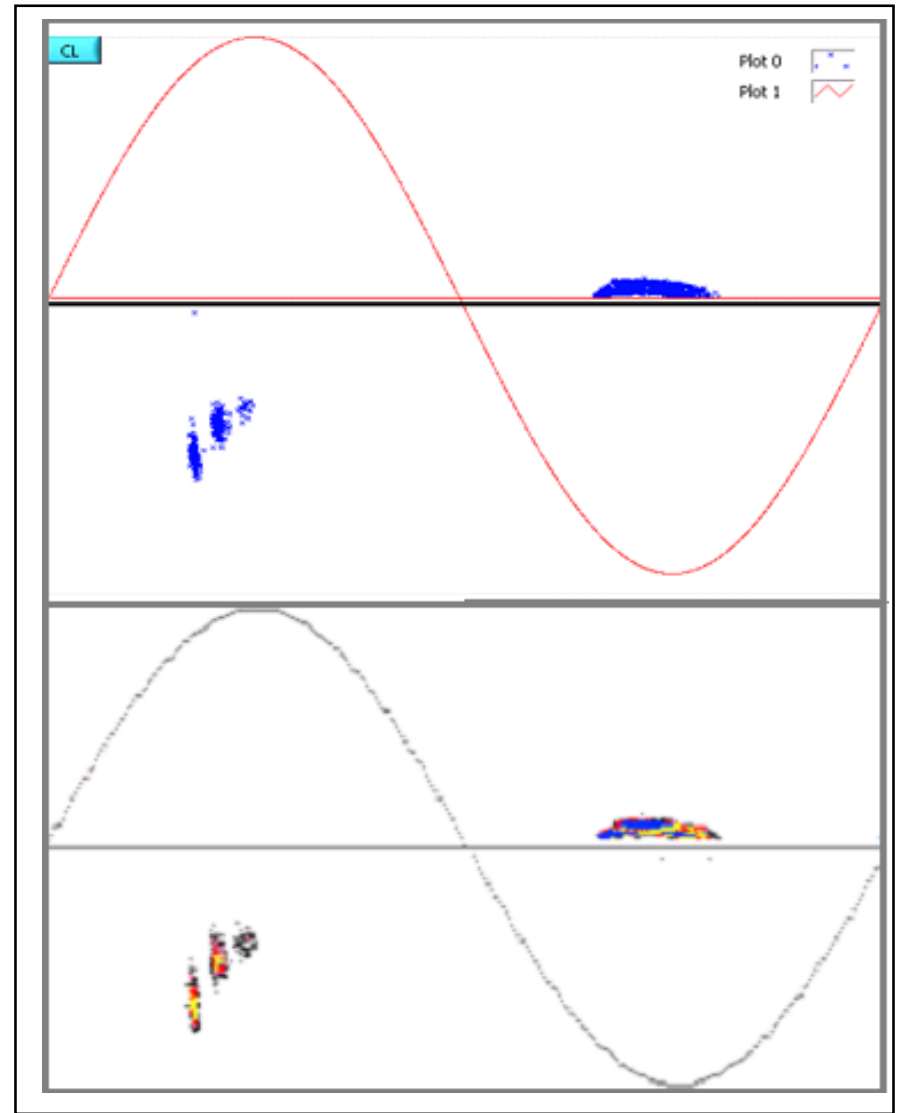

Figure 6. PRPD patterns (Corona discharge, $\mathbf{1 . 7} \mathbf{~ k V}$ ) for PD_LINEALT (up) and PD_CHECK (down).

The voltage was raised in the same test object, up to 2.5 $\mathrm{kVrms}$ with the aim of checking the acquisition system performance. The acquisition results from both systems are shown in Table II.

TABLE II. COMPARISON OF DATA FROM SYSTEM DEVELOPMENT AND PD CHECK $(2.5 \mathbf{~ K V})$

\begin{tabular}{|l|c|c|l|c|c|}
\hline \multicolumn{3}{|c|}{ PD_LINEALT } & \multicolumn{3}{c|}{ PD_CHECK } \\
\hline $\begin{array}{l}\text { HALF } \\
\text { CYCLE }\end{array}$ & + & - & $\begin{array}{l}\text { HALF } \\
\text { CYCLE }\end{array}$ & + & - \\
\hline $\begin{array}{l}\text { N } \\
\text { DISCHARGES }\end{array}$ & 858 & 8660 & $\begin{array}{l}\text { N } \\
\text { DISCHARGES }\end{array}$ & 884 & 9014 \\
\hline $\boldsymbol{\alpha}(\mathbf{V )}$ & 0.016 & 0.004 & $\boldsymbol{\alpha}(\mathbf{V})$ & 0.0373 & 0.0078 \\
\hline $\boldsymbol{\beta}$ & 2.059 & 10.48 & $\boldsymbol{\beta}$ & 1.630 & 7.014 \\
\hline $\mathbf{Q}_{\max 95 \%}(\mathbf{V})$ & 0.039 & 0.005 & $\mathbf{Q}_{\max 95 \%}(\mathbf{V})$ & 0.0891 & 0.0117 \\
\hline $\mathbf{N}_{\mathbf{W}}$ & 5.9 & 60.1 & $\mathbf{N}_{\mathbf{W}}$ & 5.80 & 58.9 \\
\hline
\end{tabular}

As expected, if the voltage level applied to the test object is increased, the number of partial discharges per cycle $(N w)$ increases significantly as well, both for $P D C H E C K$ and PD_LINEALT. Notice that the value for both systems is almost the same with a small difference of $2 \%$. 
The parameter $\beta$, for both measuring systems, shows that the amplitude variability in the positive half cycle has increased (more variability between the minimum and maximum detected PD) and has decreased in the negative half cycle (minor variability between the minimum and maximum detected PD) for higher voltages.

\section{B. Surface Discharges}

The PDIV for the test object twisted pairs was around 1 $\mathrm{kVrms}$ and every measurement was made at this voltage level. Table III and Fig. 7 show the statistical parameters and PRPD patterns for both systems, respectively.

TABLE III. COMPARISON OF DATA FROM PROPOSED SYSTEM AND PD_CHECK FOR TEST OBJECT TWISTED PAIRS (1 KV)

\begin{tabular}{|l|c|c|l|c|c|}
\hline \multicolumn{3}{|c|}{ PD_LINEALT } & \multicolumn{3}{c|}{ PD_CHECK } \\
\hline $\begin{array}{l}\text { HALF } \\
\text { CYCLE }\end{array}$ & + & - & $\begin{array}{l}\text { HALF } \\
\text { CYCLE }\end{array}$ & + & - \\
\hline $\begin{array}{l}\text { N DISCHARGES } \\
\boldsymbol{\alpha}(\mathbf{V})\end{array}$ & 12379 & 12972 & $\begin{array}{l}\mathbf{N}^{\mathbf{0}} \\
\text { DISCHARGES }\end{array}$ & 12636 & 12963 \\
\hline $\boldsymbol{\beta}$ & 0.0280 & 0.0273 & $\boldsymbol{\alpha}(\mathbf{V})$ & 0.0383 & 0.0432 \\
\hline $\mathbf{Q}_{\max 95 \%}(\mathbf{V})$ & 0.0659 & 0.0640 & $\mathbf{Q}_{\max 95 \%}(\mathbf{V})$ & 0.195 & 0.191 \\
\hline $\mathbf{N}_{\mathbf{W}}$ & 11.46 & 12.01 & $\mathbf{N}_{\mathbf{W}}$ & 11 & 12 \\
\hline
\end{tabular}

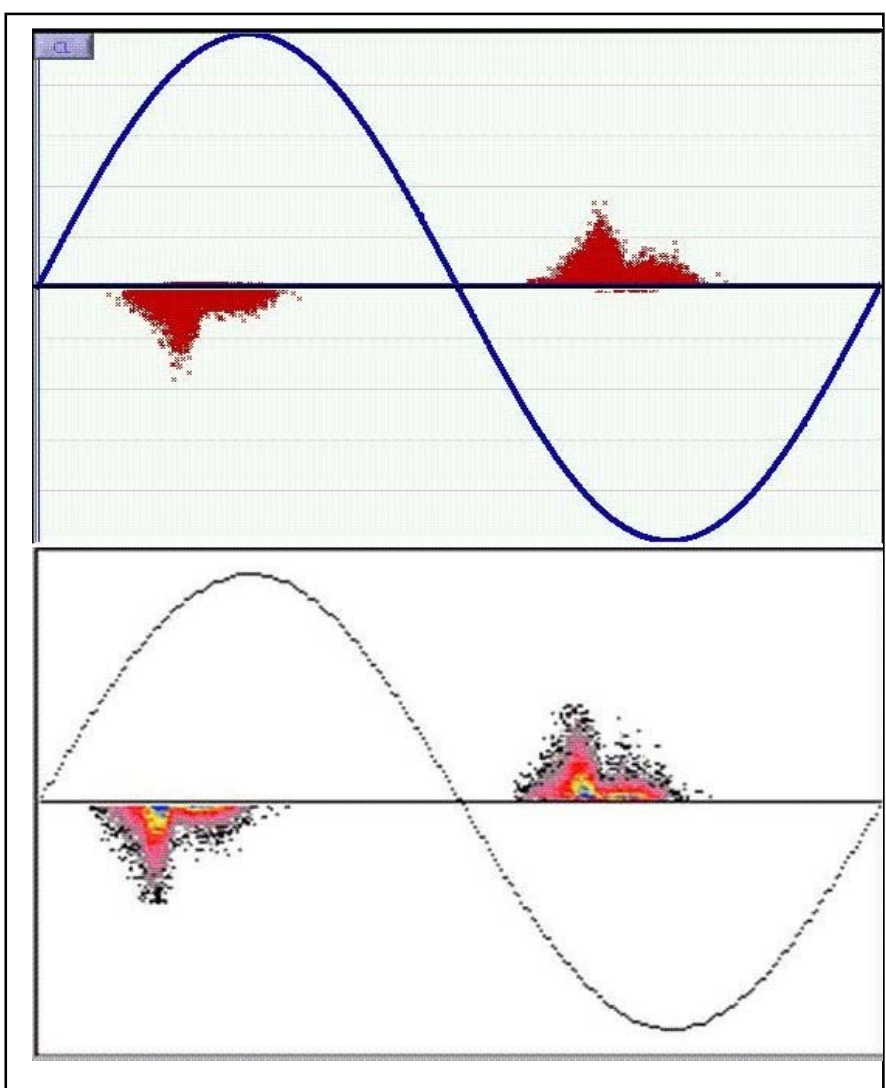

Figure 7. PRPD patterns (surface discharges, $\mathbf{1} \mathbf{k V}$ ) for PD_LINEALT (up) and PD CHECK (down).
PRPD patterns in Fig. 7 are expected from typical surface discharge sources, which lead to high PDs magnitudes for the maximum applied voltages and high magnitude dispersion (low $\beta$ ). The high symmetry for positive and negative PDs distributions ( $N_{w}$ and Weibull parameters) is observed for both acquistion systems.

\section{Internal Discharges}

In the case of oil impregnated insulating papers, measurements were made for a voltage level of $5.7 \mathrm{kVrms}$. The results obtained for the statistical parameters for both measurement systems are shown in Table IV. Fig. 8 shows the PRPD patterns.

TABLE IV. COMPARISON OF DATA FROM PROPOSED SYSTEM AND PD_CHECK FOR OIL IMPREGNATED INSULATING PAPERS $(\mathbf{5 . 7} \mathbf{~ K V})$

\begin{tabular}{|l|c|c|l|c|c|}
\hline \multicolumn{3}{|c|}{ PD_LINEALT } & \multicolumn{3}{c|}{ PD_CHECK } \\
\hline $\begin{array}{l}\text { HALF } \\
\text { CYCLE }\end{array}$ & + & - & $\begin{array}{l}\text { HALF } \\
\text { CYCLE }\end{array}$ & + & - \\
\hline $\begin{array}{l}\text { N DISCHARGES } \\
\text { NIV) }\end{array}$ & 14748 & 20199 & $\begin{array}{l}\text { N } \\
\text { DISCHARGES }\end{array}$ & 19036 & 20179 \\
\hline $\boldsymbol{\beta}$ & 0.0712 & 0.0930 & $\boldsymbol{\alpha}(\mathbf{V})$ & 0.150 & 0.200 \\
\hline $\mathbf{Q}_{\max 95}(\mathbf{V})$ & 0.1051 & 0.1373 & $\mathbf{Q}_{\max 95 \%}(\mathbf{V})$ & 0.496 & 0.458 \\
\hline $\mathbf{N}_{\mathbf{W}}$ & 212 & 290.37 & $\mathbf{N}_{\mathbf{W}}$ & 220 & 275.6 \\
\hline
\end{tabular}

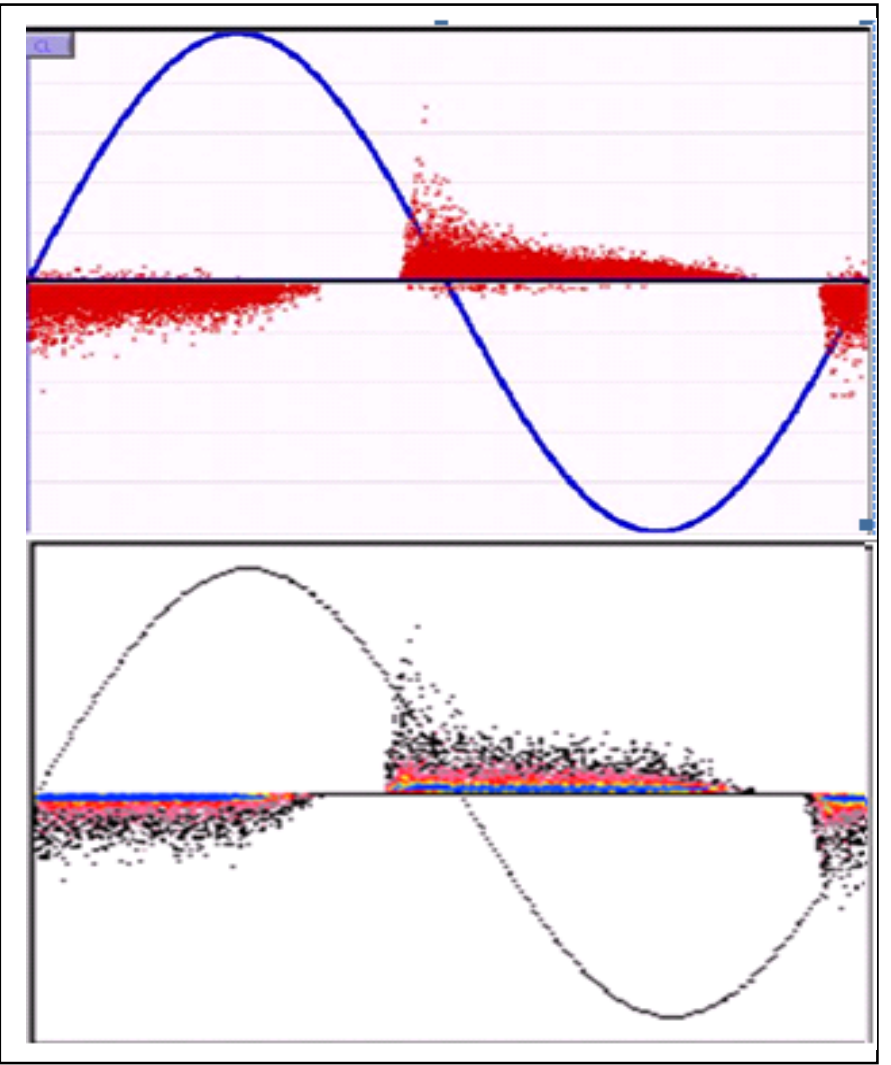

Figure 8. PRPD patterns (internal discharges, $\mathbf{5 . 7} \mathbf{~ k V}$ ) for PD_LINEALT (up) and PD CHECK (down). 
Fig. 8 shows typical internal discharge PRPD patterns where higher PDs magnitudes are synchronized to the maximum applied voltage slope and PDs magnitudes show great dispersion (low $\beta$ ).

\section{COMPARISON BETWEEN ACQUISITION SOFTWARES.}

PDs pulse count $\left(N\right.$ and $N_{w}$ ) and statistical adjustment $(\beta)$ give similar results for all the test objects and applied voltages as can be observed in Fig. 5 and Fig. 8. Moreover, PRPD patterns in each measurement lead to similar shapes. Statistical magnitudes ( $\alpha$ y $\left.Q_{\max 95 \%}\right)$ show similar tendencies, but quantitatively, the amplitudes of the PDs acquired with both systems are different because the gain of the acquisition hardware is also different (and unknown for $P D_{-} C H E C K$ ). Thus, a direct comparison of these statistical magnitudes is not valid.

The overall user interface of the PDs acquisition system is shown in Fig. 9. The PRPD pattern and PD pulse waveform are displayed in the left part of the visualization window and the calculated statistical parameters $\left(N_{w}, \alpha, \beta, Q_{\max 95 \%}\right.$, and $r$ from least square regression) are shown in the right one.

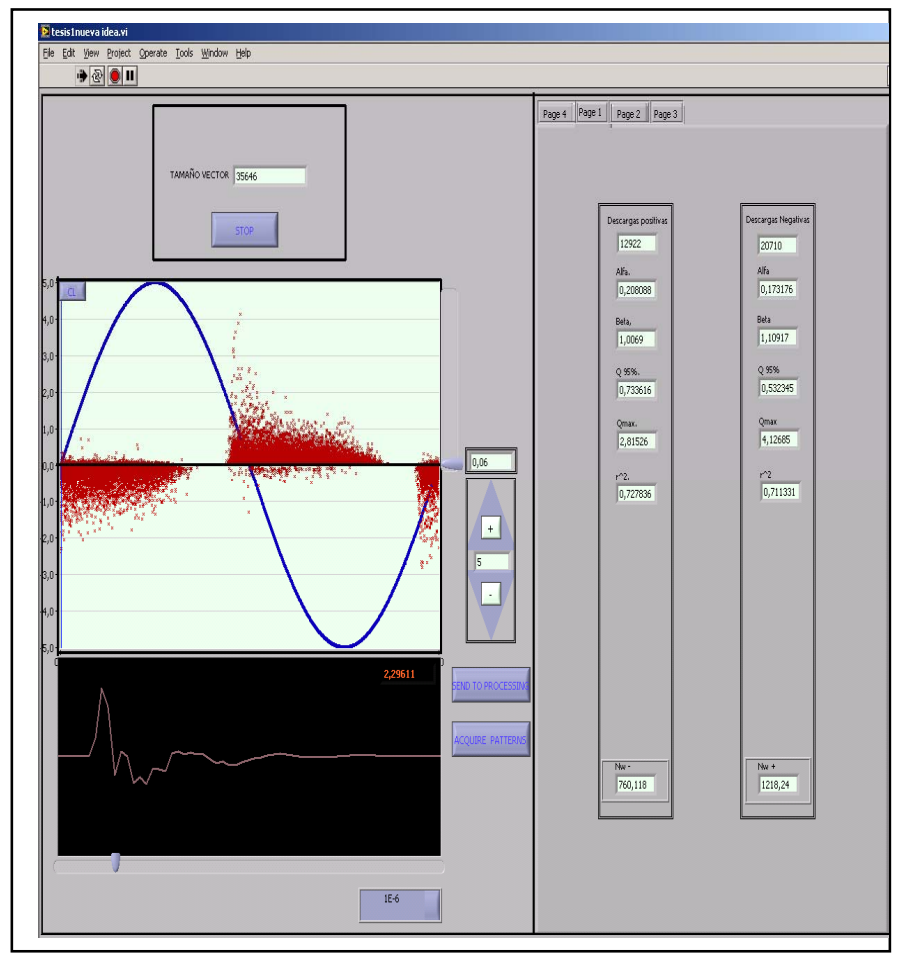

Figure 9. Visualization window for PD_LINEALT.

\section{CONCLUSIONS}

In this paper the authors have presented the main difficulties and challenges in the development of a Partial
Discharges acquisition system able to measure real time PRPD patterns and waveforms.

In order to solve the problem of oscillations from acquired PDs pulse signals, a detection algorithm has been implemented to identify correctly the amplitude and polarity of these pulses.

A ZCD incorporated into the detection algorithm has been used to set the beginning of PD pulse acquisition according to a reference signal.

Statistical data from PRPD can be calculated upon user requests without opening different software, because the calculations are made on-line in RAM.

The obtained data for each test object (point-air-plane configuration, twisted pairs and oil-paper system) and for different voltages levels have been compared to those from a commercial PDs detection system. The similarity in the data validated the performance of the proposed system.

\section{REFERENCES}

[1] F. Kreuger, "Partial Discharge Detection in High Voltage Equipment", Butterworth \& Co., Kent, pp 52-102, 1989.

[2] G. Stone, E. Boutler, I. Culbert, "Electrical Insulation for Rotating Machines: Design, Evaluation, Aging, Testing and Repair", New Jersey, IEEE Press Series on Power Engineering, Wiley Interscience, 2004, pp 295-307, ISBN 0-471-44506-1.

[3] P. Morshuis, "Degradation of Solid Dielectrics due to internal partial discharge: Some thoughts on progress made and where to go now", IEEE Transactions On Dielectrics and Electrical Insulation, Vol 12, pp 905-913, Dec 2005.

[4] IEC 60270, "High Voltage Test Techniques. Partial Discharge Measurements, 3.0 Ed", 2000.

[5] A. Krivda, "Recognition of Discharges. Discrimination and Classification", Delft Press, 1995.

[6] A. Lapp, H. G. Kranz, "The use of the CIGRE data format for PD diagnosis applications", IEEE Transactions On Dielectrics and Electrical Insulation, Vol 7, pp 102-112, Feb 2000.

[7] L. A. Dissado, J. C. Fothergill, "Electrical Degradation and Breakdown in Polymers", London, IEE Materials and Devices Series, 1992, pp. 319339, ISBN 0-86341-196-7.

[8] A. Cavallini, G.C. Montanari, A. Contin y F. Puletti, "A New Approach to the Diagnosis of Solid Insulation Systems Based on PD Signal Inference", IEEE Electrical Insulation Magazine, Vol 19, pp 29-30 March-April 2003.

[9] H. Okubo, N. Hayakawa, "A Novel Technique for Partial Discharge and Breakdown Investigation Based on Current Pulse Waveform Analysis",IEEE Transactions on Dielectrics and Electrical Insulation, Vol.12, pp 736-744, August 2005.

[10] G. Robles, J. M. Martínez, M. Rojas, and J. Sanz, "Inductive sensor for measuring high frequency partial discharges within electrical insulation", IEEE Transactions on Instrumentation and Measurement, vol. 58, pp.3907-3913, Nov 2009.

[11] A. Jambula, V. Lakdawala, and P. Basappa, "Development of a Digital Acquisition System for Partial Discharge Measurement and Analyses", IEEE Electrical Insulation Conference, pp 60-63, Nov 2009. 